\title{
External and internal grouping characteristics of juvenile walleye pollock in the Eastern Bering Sea
}

\author{
Sarah C. Stienessen ${ }^{1,4, *}$, Christopher D. Wilson ${ }^{1}$, Thomas C. Weber ${ }^{2}$ and Julia K. Parrish ${ }^{3}$ \\ ${ }^{1}$ NOAA, National Marine Fisheries Service, Alaska Fisheries Science Center, Seattle, WA, USA \\ 2 Center for Coastal and Ocean Mapping, University of New Hampshire, Durham, NH, USA \\ ${ }^{3}$ School of Aquatic and Fishery Sciences University of Washington, Seattle, WA, USA \\ ${ }^{4}$ Alaska Fisheries Science Center 7600 Sand Point Way NE, Seattle, WA 98115, USA
}

Received 12 December 2018 / Accepted 22 June 2019

Handling Editor: Verena Trenkel

\begin{abstract}
Size and shape patterns of fish groups are collective outcomes of interactions among members. Consequently, group-level patterns are often affected when any member responds to changes in their internal state, external state, and environment. To determine how groups of fish respond to components of their physical and ecological environment, and whether the response is influenced by a component of their external state (i.e., fish age), we used a multibeam system to collect three-dimensional grouping characteristics of 5 age categories of juvenile walleye pollock (age 1, age 2, age 3, mixed ages 1 and 2, and mixed ages 2 and 3) across the eastern Bering Sea shelf over two consecutive years (2009-2010). Grouping data were expressed as metrics that described group size (length, height), shape (roundness, spread), internal structure (density, internal heterogeneity), and position (depth, distance above bottom). Physical data (water temperature measurements) were collected with temperature-depth probes, and ecological data (densities of predators and prey - adult walleye pollock and euphausiids, respectively) were collected with an EK60 vertical echosounder. Juvenile pollock maintained a relatively constant shape, size-dependent density (number fish/mean body length ${ }^{3}$ ), and internal horizontal heterogeneity among age categories and in the presence of predators and prey. There were changes to group structure in the face of local physical forcing. Groups tended to move towards the seafloor when bottom waters became warmer, and groups became vertically shorter, denser, and had more variation in horizontal internal density as group depth increased. These results are explored in relation to the value and limitations of using multibeam data to describe how external and internal group structure map onto environmental influences.
\end{abstract}

Keywords: Walleye pollock / fish groups / size / shape / structure / temperature / depth / predator / prey

\section{Introduction}

Within schooling fish, interactions between members can produce group-level patterns and structure (Couzin and Krause, 2003; Rieucau et al., 2015, 2016) - sometimes referred to as the "emergent properties" of the group (Clark et al., 1997) - including group size, shape (Parrish and Edelstein-Keshet, 1999), and internal packing density. Changes in group-level properties allow individuals to maximize their fitness as conditions change. For example, grouped walleye pollock, Gadus chalcogrammus (formerly known as Theragra chalcogramma; Page et al., 2013), are more successful at exploiting ephemeral food patches

*Corresponding author: sarah.stienessen@noaa.gov
(Baird et al., 1991; Ryer and Olla, 1992), and walleye pollock group cohesion increases as prey distribution switches from dispersed to clumped (Sogard and Olla, 1997). Within a group, individuals may position themselves relative to other individuals of similar sizes in response to predator and prey considerations (e.g., Svensson et al., 2000; Maes and Ollevier, 2002). Shifts toward a more favorable group structure are thus the result, in part, of individuals responding to their particular interpretation of the local environment (Bertrand et al., 2006; Gerlotto et al., 2006), filtered through individual internal (e.g., physiology, experience: Seebacher and Krause, 2017; Cantor and Farine, 2018) and external (e.g., fish size: Couzin and Krause, 2003) states. However, not all group behaviors are beneficial; some may be detrimental in specific situations. For example, it is generally thought members in a group benefit from greater group density when a predator is nearby 
(Hamilton, 1971), but some predators (e.g., killer whales) increase feeding efficiency by cooperatively herding fish into tight balls (Similä and Ugarte, 1993; Nøttestad and Axelsen, 1999). The key to understanding how group structure is maintained is to determine which individual behaviors produce group-level patterns that are functionally advantageous to its members (Parrish et al., 2002).

To identify how interactions between members produce group-level patterns, studies have tracked the trajectories of individual fish and related those patterns to overall group structure (e.g., Tien et al., 2004; Viscido et al., 2004; Katz et al., 2011; Stienessen and Parrish, 2013). These types of observations are limited because of the large effort needed to extract small amounts of quantitative data (i.e., the difficulty in tracking relatively large, fast animals with overlapping trajectories over extended periods of time). Therefore, simulation studies have been frequently employed in tandem with, or as an alternative to, empirical observations to show how intricate group structure is created by straightforward individual interactions (e.g., Couzin et al., 2002, 2005; Viscido et al., 2005; Conradt et al., 2009; Guttal and Couzin, 2010; Berdahl et al., 2013; Hein et al., 2015; Swain et al., 2015; Jolles et al., 2017). Even so, it can be difficult to determine which behaviors are biologically relevant, and these types of studies may not be able to provide enough information about what the group is doing, especially in a realistic, unconfined, threedimensional setting.

It is possible to characterize in situ responses of fish to their environment by quantifying emergent properties at the group scale; that is, describing group size (e.g., group length, height), shape (e.g., group perimeter-to-area ratio) and density (e.g., number of individuals/area). A lot of this research has focused on using acoustic data to depict fish behavior including predator-prey interactions (DeBlois and Rose, 1995; Mackinson et al., 1999), reactions to commercial fisheries (Wilson et al., 2003; Walline et al., 2012), migration patterns (Rose, 1993), and reactions to changes in the physical environment (Nero and Magnuson, 1989; Barange, 1994; Swartzman et al., 1994; Soria et al., 2003). However, limitations in associated sampling technologies at the group scale essentially prevent direct observations of individual group members.

There is evidence to suggest internal group structure (e.g., areas of high-density nuclei and unfilled vacuoles) observed within an acoustically detected group represent patterns that arise from interactions between members (Gerlotto and Paramo, 2003; Paramo et al., 2010). Such "internal heterogeneity" may be indicative of group membership. Relatively high heterogeneity (i.e., higher degree of nuclei and/ or vacuoles) can mean diversity of fish within a group, because individuals of different ages, sizes, or species likely have different physical and physiological limitations (e.g., average or maximum speed, metabolic rates), which can influence the distribution of fish (Grünbaum et al., 2005; Viscido et al., 2007) and induce sorting (Hemelrijk and Kunz, 2005; Seebacher and Krause, 2017). Internal heterogeneity may also be indicative of ecological interactions. For example, Gerlotto et al. (2006) were able to detect a "wave of agitation" that spread through the school when a predator approached and noted the internal school structure was more homogeneous (i.e., had more consistent interfish distances between members) after the predator had passed. These findings

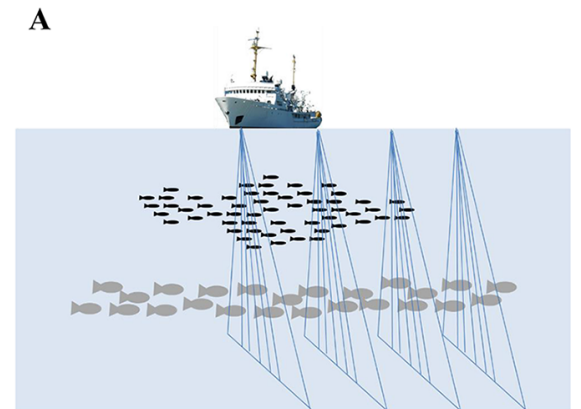

B

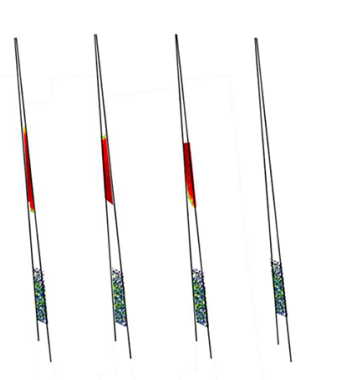

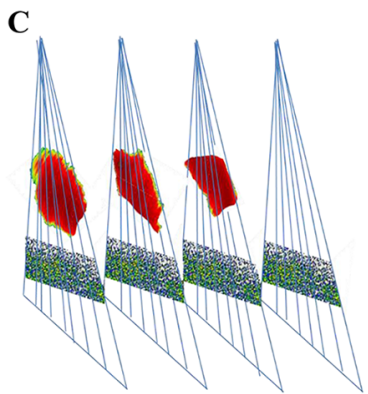

Fig. 1. (A) Schematic of the insonification of two fish groups (e.g., juvenile fish - shallower, predator - deeper) with a 7-beam multibeam sonar. In this depiction, part of the juvenile group has been insonified over three consecutive transmitted acoustic signals (i.e., pings) and part of the predators have been insonified over four consecutive transmitted acoustic signals. (B) The associated backscatter characterizes the two-dimensional structure of the insonified part of the groups. (C) The associated backscatter characterizes the three-dimensional structure of the insonified part of the group. The color scale green-to- dark red represents low to high backscatter values, respectively.

suggest that structural heterogeneity may be a proxy for both the degree of heterogeneity of group membership (i.e., size, age, or species) as well as external influences (e.g., ecological or other environmental forcing).

The goal of this study was to examine the external and internal group structure of in situ groups of fish to ask more comprehensive questions about the degree to which group structure (i.e., emergent properties) map onto environmental influences. We did this by exploring the connection between measured group properties, including internal heterogeneity, the degree of age difference (proxied by size) within the group, and the local and regional scale influences of the physical (temperature, shelf depth) and ecological (predator, prey) environment.

We took advantage of data collected with a Simrad multibeam echosounder (ME70) system during an ongoing fishery monitoring program of walleye pollock in the eastern Bering Sea. The ME70 is a multibeam system deisgned specifically for fishery research applications. It has very low side lobes and is dedicated for collection of data in the water column (Trenkel et al., 2008). It can insonify entire groups in situ, effectively allowing us to measure specific properties of the three-dimensional group structure (Fig. 1), and when calibrated, it can provide fish density estimates. We then analyzed the grouping patterns as a function of independently 
assessed physical and ecological factors. Walleye pollock (hereafter "pollock") are one of the most abundant and commercially important fish in the Bering Sea (Kim, 1990). Although adults are semi-demersal and form aggregations that can extend for miles near the seafloor, juveniles are often found throughout the water column in discrete groups with welldefined edges (Wilson et al., 2003; Walline et al., 2012) which allow for readily measured emergent properties (Reid et al., 2000). Additionally, strong cohorts of juvenile walleye pollock move though the population over consecutive years that can result in groups composed of multiple age classes of juveniles (e.g., Stienessen and Wilson, 2008; Honkalehto et al., 2010, 2012). This allows for examination of the role that external state (i.e., age, proxied by size) plays on emergent group properties.

We used the three-dimensional data provided by the ME70 to test three specific hypotheses. First, given that predator avoidance and foraging success provide two of the main benefits to group living, we expected that local predator and/or prey density would affect the responses of fish as evidenced by group structure, both external (i.e., size and shape) and internal (i.e., density and internal heterogeneity). Second, because habitat features (e.g., thermoclines) have been shown to influence the vertical distribution of fish species (Traynor, 1986; Swartzman et al., 1994) but not their group metrics (Swartzman, 1997; Soria et al., 2003), we expected that measures of the physical environment (i.e., temperature and shelf depth) would influence vertical position of the group in the water column rather than group internal and external structure. Third, because sorting can occur in groups with different size fish (Hemelrijk and Kunz, 2005), we expected groups with differences in membership (i.e., fish age/size) would have a higher degree of internal heterogeneity.

\section{Materials and methods}

We extracted and quantified emergent properties of juvenile pollock groups from the data collected with the ME70 and examined the influence of the local environment on these properties by considering ecosystem components and interactions. That is, we described basic associations among juvenile pollock physical habitat (i.e., water temperature and depth), one of their main predators (i.e., adult pollock: Bailey, 1989), and a common prey species (i.e., euphausiids: Dwyer et al., 1987; Aydin and Mueter, 2007) to understand how each of these features influences juvenile pollock grouping behavior.

\subsection{Field methods}

Acoustic trawl surveys were conducted onboard the NOAA ship Oscar Dyson during the summers of 2009 and 2010 and consisted of a series of north-south parallel transects uniformly spaced $20 \mathrm{nmi}$ apart over the Bering Sea shelf from Port Moller, Alaska, to the U.S.-Russia Convention Line in the area around Cape Navarin, Russia (Fig. 2; Honkalehto et al., 2010, 2012). Acoustic data were collected during daylight hours (typically between 6:00 and 24:00 local time), over bottom depths ranging between $100-150 \mathrm{~m}$, with a Simrad EK60 scientific echo sounding system (Simrad, 2004;
Bodholt and Solli, 1992), which used 5 split-beam transducers $(18,38,70,120$, and $200 \mathrm{kHz})$, and with a Simrad ME70 multibeam echo sounder (Trenkel et al., 2008). The ME70 was configured to operate with 31 symmetrical split-beams, the middle beam being vertically-oriented (i.e., steered at $0^{\circ}$ ). The beams in this configuration ranged from the spherical $2.8^{\circ}$ nadir beam $\left(0^{\circ}\right)$ operating at $117 \mathrm{kHz}$ to two $4.5^{\circ}$ alongship by $11.0^{\circ}$ athwartship ellipsoidal beams steered at $\pm 66^{\circ}$ and operating at $75 \mathrm{kHz}$ (Fig. 3). A $25 \mathrm{~mm}$ tungsten carbide sphere was used to calibrate each beam, except for the 2 outermost ones on each side, of the ME70 system at the beginning of the 2009 survey. We were unable to place the sphere into those 4 outer beams (they were too far away from the ship in the horizontal dimension), so the data collected by the 4 outer beams were not used in this study. This effectively made the beam configuration limited to a $100^{\circ}$ swath (steered from $\pm 50^{\circ}$ ), with outer beamwidths of $4.1^{\circ}$ alongship by $6.5^{\circ}$ athwartship that operated at $80 \mathrm{kHz}$ (Fig. 3). This configuration had a two-way sidelobes around $-70 \mathrm{~dB}$ re $1 \mathrm{~m}$. The EK60 system was calibrated at the beginning and end of both surveys, and during the middle of the 2009 survey (Honkalehto et al., 2010, 2012). Acoustic data collected with the ME70 were used to obtain metrics describing juvenile pollock grouping patterns, and acoustic data collected with an EK60 were used to obtain shelf depth and juvenile pollock predator (i.e, adult pollock) and prey (i.e., euphausiid) densities.

The EK60 and ME70 systems transmitted sequentially to avoid system interference. The ping rate for both systems was 1 ping/ $1.26 \mathrm{~s}$, and the ship averaged $5.5 \mathrm{~m} / \mathrm{s}$. This provided a nominal along track resolution of approximately $1 \mathrm{ping} / 6.9 \mathrm{~m}$, which did not allow for full acoustic coverage in the horizontal dimension (e.g., a $3^{\circ}$ beam is $2.6 \mathrm{~m}$ wide at $50 \mathrm{~m}$ depth). Only data collected deeper than $16 \mathrm{~m}$ and $20 \mathrm{~m}$ by the EK60 and ME70, respectively, were used because of the combination of placement of the transducers on the centerboard or hull (i.e., depth of the transducers in the water column) and the transmit blank zones (Simmonds and MacLennan, 2005).

Much of the watercolumn backscatter in the eastern Bering Sea is from walleye pollock (Honkalehto et al., 2011). Acoustic backscatter was attributed to adult or juvenile pollock based on the depth distribution of the aggregations, the appearance of the aggregations, and the catch composition in nearby trawl hauls (e.g., Fig. 1). Frequency-differencing was used to separate euphausiid backscatter from pollock backscatter (pollock backscatter is relatively stronger at $38 \mathrm{kHz}$ and euphausiid backscatter is relatively stronger at $120 \mathrm{kHz}$; De Robertis et al., 2010). Biological samples were collected with a larger (i.e., Aleutian Wing trawl) and a smaller (i.e., Methot) midwater net (Honkalehto et al., 2010, 2012). Catches of pollock, typically the dominant scatterer, were sampled to determine fork length (FL) to the nearest $1.0 \mathrm{~cm}$, body weight to the nearest $2.0 \mathrm{~g}$, and age of the fish. Trawl catch information was used to convert acoustic backscatter collected with the EK60 to abundance and biomass estimates, which were binned at $0.5 \mathrm{nmi}$ horizontal resolution using standard protocols (Honkalehto et al., 2008; Ressler et al., 2012).

Temperature profiles were obtained with a temperaturedepth probe attached to the trawl headrope. Expendable bathythermograph (XBT) probes and conductivity-temperature-depth (CTD) casts were also used to collect water 

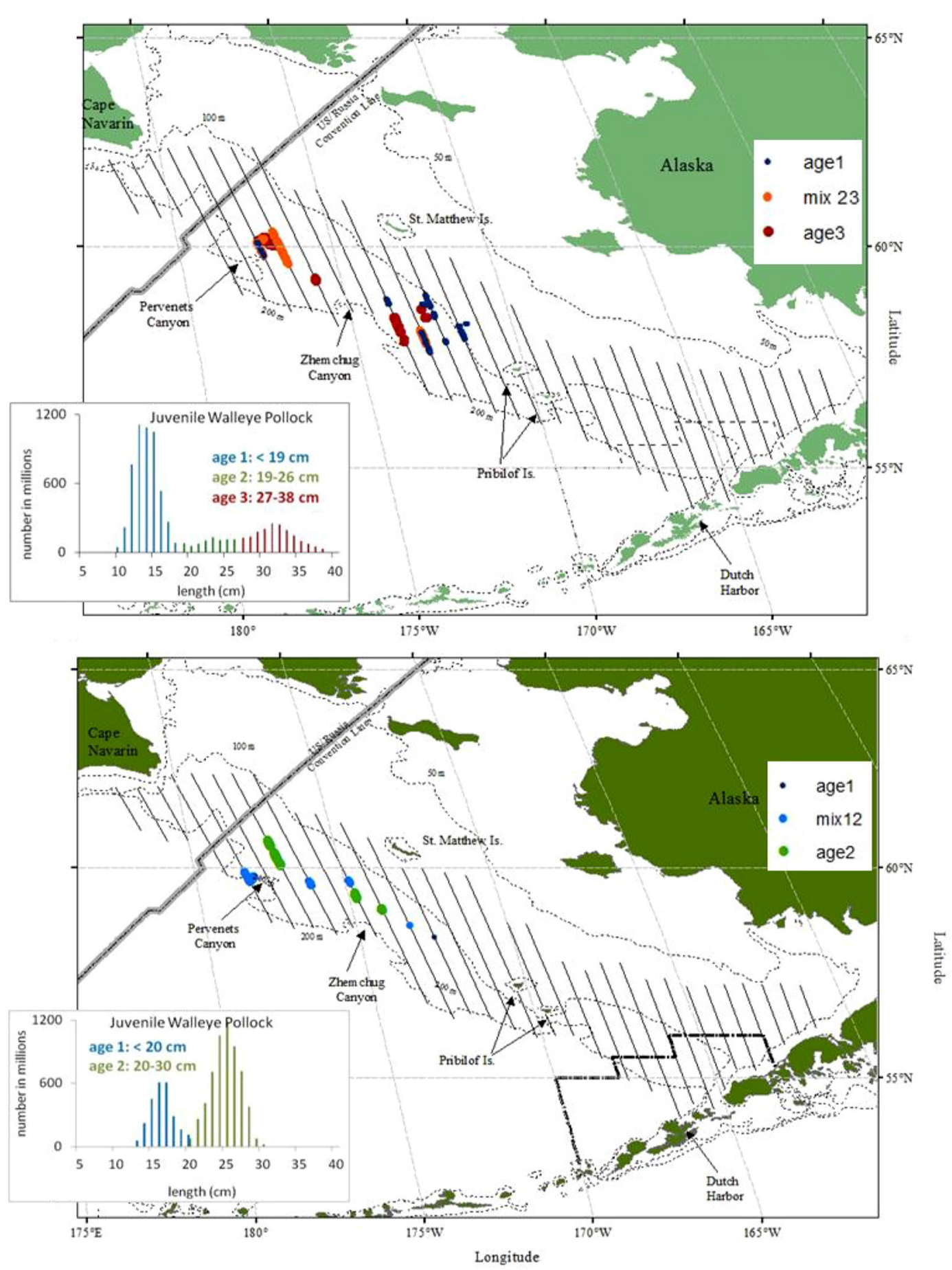

Fig. 2. The study area in the eastern Bering Sea during 2009 (top) and 2010 (bottom). Both plots show the survey tracklines and locations of fish groups by age class. Mix 12 are groups that contain both age- 1 and age- 2 fish, and mix 23 are groups that contain both age- 2 and age- 3 fish. Note that age-1 fish were detected in only a single location in 2010 .

temperature and salinity profile data at selected locations throughout the study area (Honkalehto et al., 2010, 2012).

\subsection{Defining and isolating a group}

Juvenile pollock backscatter collected with the ME70 was first isolated from other backscatter (i.e., euphausiid backscatter) and then classified into juvenile pollock groups. The former was done by applying a $-52 \mathrm{~dB}$ re $1 \mathrm{~m}$ threshold to the backscatter using Fledermaus midwater software (http:// www.qps.nl/display/fledermaus/main, Version 7.3.2b, Build 443Beta, 64-bit Edition, accessed January 2014). This threshold was selected based on a threshold sensitivity analysis conducted over a range of processing thresholds 

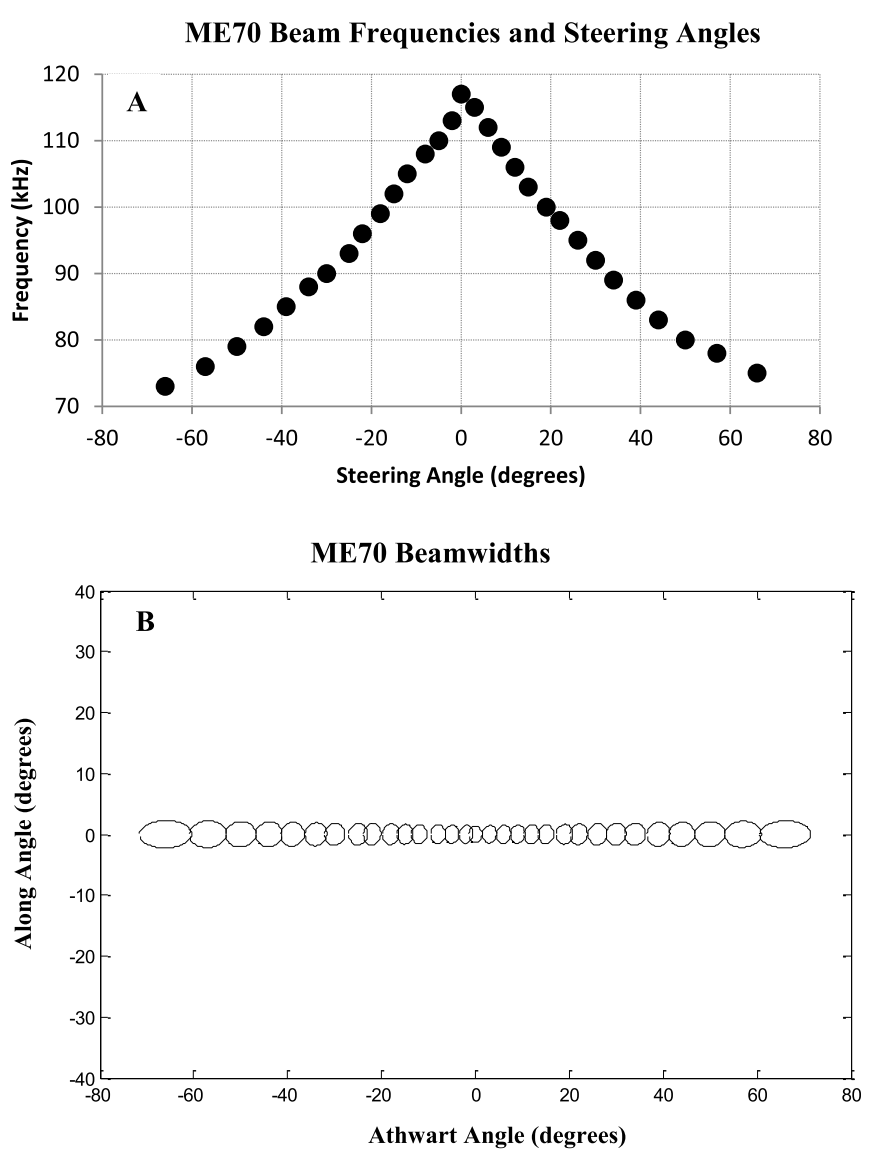

Fig. 3. The ME70 beam configuration, showing (A) the steering angle-frequency combination for each beam and (B) the beamwidths (beam opening values refer to the one-way received beams). Note the axes in Figure 2B are at different scales. Data collected in 4 outermost beams ( 2 on each side) were not used. This resulted in an effective fan width of $\pm 50^{\circ}$.

from -66 to $-48 \mathrm{~dB} \mathrm{~Sv}$. The backscatter at each processing threshold was classified into groups, and group metrics were calculated. These results indicated that group metrics stablilized around $-52 \mathrm{~dB}$ so this threshold was used to filter out pollock backscatter from other (i.e., mostly euphausiid) backscatter (see Stienessen, 2015). The end result was the generation of 3D point clouds of backscatter detections.

Juvenile pollock backscatter was attributed to 1 of 5 age categories based on haul data: age 1, age 2, age 3, mixed ages 1-2 (hereafter referred to as "mix 12"), and mixed ages 2-3 (hereafter referred to as "mix 23"). To ensure that the correct age of pollock was attributed to the backscatter, only acoustic data that were collected consistently (i.e., no gaps in backscatter lasting more than $0.5 \mathrm{nmi}$ ) up to $15 \mathrm{nmi}$ from a haul location where $100 \%$ of the trawl contained only one age category were used in this study (Williamson and Traynor, 1996; Walline, 2007).

Backscatter $(\mathrm{Sv})$ values were adjusted to correct for the effects of angular response of insonified juvenile pollock within the steered beams (Towler et al., 2003; Cutter and Demer, 2007; Holmin et al., 2012). This was done by averaging Sv values per beam (Svc) based on the evidence that the pollock were not responding to the vessel (Stienessen, 2015) and under the assumption the fish were not aligned geoghraphically.

We then classified Svc into juvenile pollock groups based on four user-defined input parameters: minimum connected distance $(10 \mathrm{~m})$, minimum connected size (25 detections), maximum horizontal linking distance $(25 \mathrm{~m})$, and maximum vertical linking distance $(5 \mathrm{~m})$ as follows. The distance between two Svc values in any direction must be less than or equal to the minimum connected distance for the backscatter to be considered part of the same group. A group had to have at least the minimum connected size to be considered an actual group. If the distance between any two groups was more than the maximum linking distance, the groups were considered separate from one another. These parameters were examined over a range of values and evaluated, and the final criteria were chosen based on their ability to provide the best definition of a juvenile walleye pollock group when compared by eye to the original echogram. The criteria chosen to define a group likely contain substantial and unknown biases. However, if the criteria are kept constant, as in the present study, they should provide useful comparative information about the variability of fish group structure (Fréon et al., 1996; Reid et al., 2000). Once juvenile pollock Svc was classified into groups, we restricted the dataset to only groups that had been wholly insonified, defined operationally as groups contained entirely within the ME70 swath exclusive of the outermost beams.

Juvenile pollock groups detected in 2009 were ultimately classified into age $1(n=459)$, $\operatorname{mix} 23(n=1259)$, or age 3 $(n=1256)$ age categories, and the groups detected in 2010 were ultimately classified into age $1(n=19)$, $\operatorname{mix} 12(n=1334)$, or age 2 age categories $(n=1406)$. Although age-1 and age- 2 fish were present both years, there was no appreciable overlap in age categories between the two years. Age- 2 fish were only observed in mix23 groups in 2009. Age-1 fish were only observed in 19 pure-aged groups or as part of mix 12 groups in 2010. Consequently, pure-age 1 groups from 2010 were added to 2009 for all analyses.

\subsection{Group metrics}

Several "group metrics" were used to describe the overall structure, or architecture, of juvenile pollock groups. These metrics fall into three general categories: external, internal, and positional. External metrics describe the overall size and shape of the group, internal metrics describe the density distribution within the group, and positional metrics describe position of the group in the water column. Most of these metrics have been previously used to characterize in situ responses of fish to their environment (e.g., DeBlois and Rose, 1995; Gerlotto and Paramo, 2003; Soria et al., 2003; Wilson et al., 2003; Gerlotto et al., 2006; Stienessen and Wilson, 2008; Walline et al., 2012).

External group structure was described with several size metrics: group length (i.e., major horizontal axis of the group; $\mathrm{m}$ ), width (i.e., greatest horizontal distance perpendicular to group length; $\mathrm{m})$, height $(\mathrm{m})$, surface area $\left(\mathrm{m}^{2}\right)$, and volume $\left(\mathrm{m}^{3}\right.$; Tab. 1). Because there was a high degree of correlation between group length, width, surface area, and volume ( $r>0.88$ across all pairwise comparisons), length was used as the representative of these 4 metrics, restricting length and 
Table 1. Names, symbols, and definitions of group metrics and the various indices, intermediary equations, and scattering quantities used to calculate them.

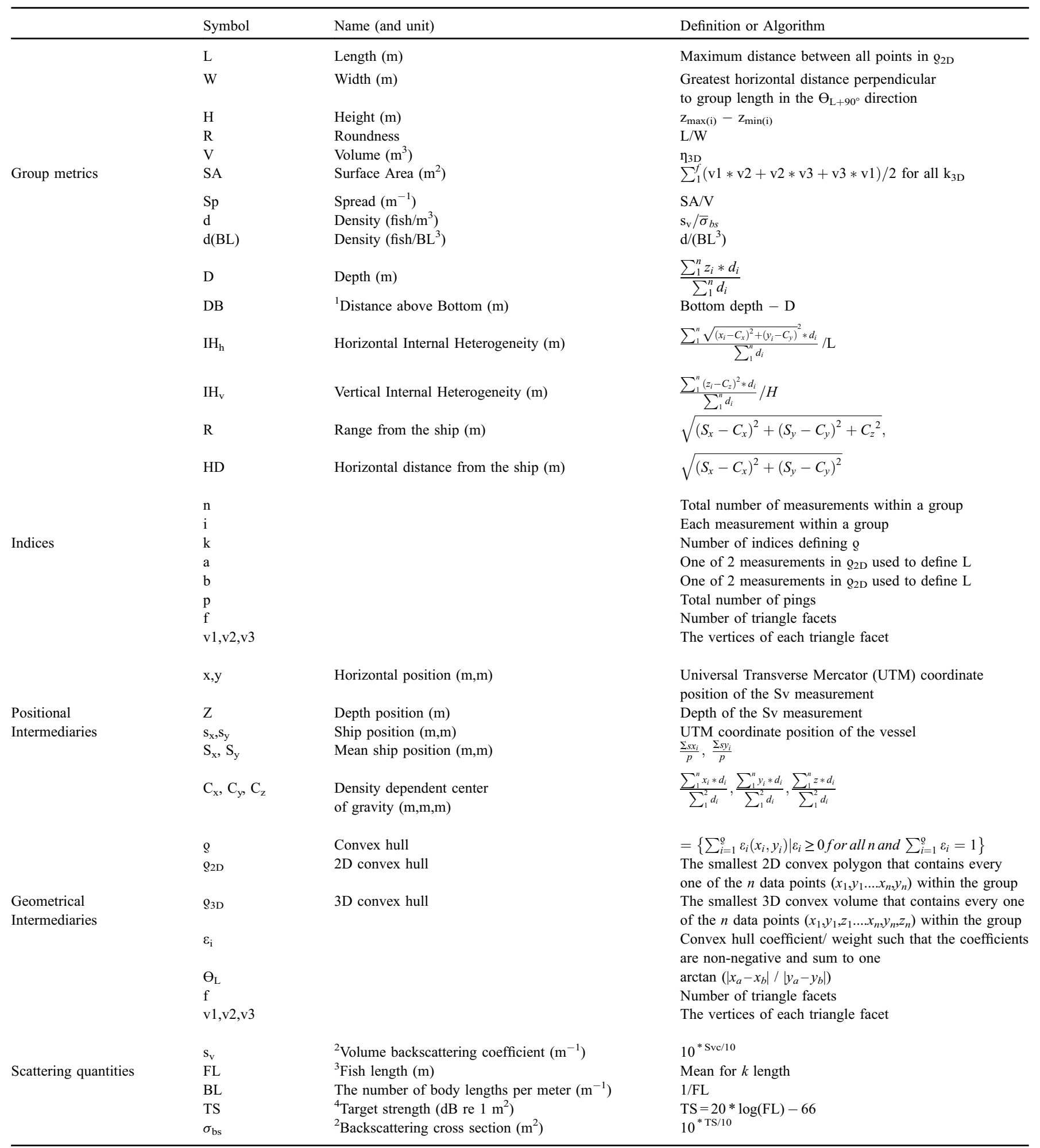

${ }^{1}$ Bottom depth was taken from the nearest $(<15 \mathrm{nmi})$ haul location.

${ }^{2}$ MacLennan et al. (2002).

${ }^{3}$ Based on the population length composition from the nearest $(<15 \mathrm{nmi})$ haul location.

${ }^{4} \mathrm{TS}$ to $\mathrm{FL}_{\mathrm{cm}}$ model for walleye pollock from Foote and Traynor (1988). 
height as the representative simple geometric measurements of school size. The size metrics were used to calculate two shape metrics: group roundness and spread $\left(\mathrm{m}^{-1}\right.$; Tab. 1). Because juvenile pollock groups are more spread out in the horizontal plane than the vertical plane (Wilson et al., 2003; Stienessen and Wilson, 2008; Walline et al., 2012), and the majority of forward motion of fish groups is typically in the horizontal plane (Bumann et al., 1997), we chose to describe the horizontal shape of walleye pollock groups. To do this, we calculated roundness, a ratio of group length to group width. A smaller roundness value (minimized at 1 , a circle) indicates the group is more horizontally circular, whereas a larger value indicates that the group is more horizontally oblong. Spread is the ratio of group surface area to volume and, along with group size, describes the consistency of 3D group shape. If the spread stays constant over various group sizes, it suggests that smaller groups are more spherical and larger groups are more elliptical or irregular. However, if spread decreases as group size increases, it suggests that group shape is more constant among various group sizes. Length, width, and roundness were also corrected for the effects of beam spreading (Stienessen, 2015) according to Diner (2001). These corrections utilize a form of corrected school length increase which is a function of nominal beamwith.

Internal group structure was described with several metrics: group density and internal heterogeneity. To be consistent with many other in situ studies which have described acoustic data with density calculated as a function of backscatter per volume (e.g., DeBlois and Rose, 1995; Swartzman et al., 1994; Paramo et al., 2007; Stienessen and Wilson, 2008; Walline et al., 2012), we calculated juvenile pollock group density as fish per volume based on the average fork length of juvenile pollock in the nearest haul $\left(\mathrm{fish} / \mathrm{m}^{3}\right.$; Tab. 1). However, because the juvenile pollock in our study were not the same size, we standardized this result by also calculating juvenile pollock group density as a function of body length (number of fish/mean $\mathrm{BL}^{3}$; Tab. 1; e.g., Pitcher and Partridge, 1979) based on catch data. Size-dependent density describes interfish spacing relative to fish size (i.e., body length; BL), whereas volume-dependent density describes interfish spacing relative to a constant volume (i.e., $1 \mathrm{~m}^{3}$ ). In a situation where small and large fish both maintain $1 \mathrm{BL}$ between neighbors, there would be more small fish in $1 \mathrm{~m}^{3}$ than there would be large fish. Density was also corrected for the effects of beam spreading (Stienessen, 2015) according to Diner (2001). To represent the organization of juvenile pollock within a group (i.e., to parameterize whether the fish are forming clusters, or nuclei, within the group), we described the variance in group density $\left(\mathrm{m}^{2}, \mathrm{Tab}\right.$. 1). This variance was standardized by group length and group height to produce horizontal and vertical internal heterogeneities, respectively ( $\mathrm{m}$; Tab. 1). Groups with lower (or higher) internal heterogeneities have a more uniform (or clustered) spacing between fish.

A limitation to using Diner's corrections is that the group dementions need to be large compared to the beamwidth. Therefore, we only considered groups, and applied the corrections, when the normalized group length relative to beamwidth was larger than 1.5 (Diner, 2001). After applying Diner's corrections, there is an extremely low correlation between group range to the ship and each group metric (i.e., correlation $=0.02$ [range and length], -0.02 [width], 0.09 [roundness], 0.01 [spread], -0.06 [density], and 0.11 [horizontal inertia]). This indicates that observed changes in group metrics were not dependent on range. Thus, patterns were either large enough to be adequately captured by the coarser resolution found at deeper depths, or they were too small to be adequately captured by the finer resolution found at shallower depths.

Finally, three positional metrics of the group in the water column were calculated based on the group's densitydependent center of gravity: group depth, distance above bottom, and range from the ship ( $\mathrm{m}$; Tab. 1). To investigate the potential that vessel avoidance by the fish (De Robertis and Handegard, 2012) might confound our results, all descriptors were examined as a function of horizontal distance from the vessel at three depth bins: $20-50 \mathrm{~m}, 51-100 \mathrm{~m}$, and $101-150 \mathrm{~m}$. No trends were detected that could be attributed to vessel avoidance (Stienessen, 2015).

\subsection{Environmental factors: ecological and physical}

Two categories of environmental factors were examined: ecological factors (i.e., predator and prey densities) and physical factors (i.e., water temperature and shelf depth). The influence of predators (here proxied by the $\mathrm{s}_{\mathrm{A}}\left(\mathrm{m}^{2} \mathrm{mni}^{-2}\right.$; MacLennan et al., 2002) of adult pollock) and prey (here proxied by the $\mathrm{kg}$ of euphausiids) was assessed as a function of the distance between each juvenile pollock group and the nearest predator and prey, respectively. Three water temperature measurements were associated with each group based on the group's density-dependent center of gravity: sea surface temperature, temperature at the depth of the group ("group temperature"), and bottom temperature. Summer sea surface and bottom temperatures are related to the presence or absence of sea ice during the previous winter (Stabeno et al., 2012) and characterize larger-scale temperature patterns over the eastern Bering Sea; whereas group temperature describes the water temperature at the exact depth of the group. These values were determined by matching the geographic surface location, depth of the group, and seafloor depth below the group to the corresponding temperatures from the nearest $(<15 \mathrm{nmi}) \mathrm{XBT}$ or CTD profile, conducted within a day of the acoustics data collection.

\subsection{Statistical analyses}

Because walleye pollock exhibit diel periodicity in their grouping behavior (Ryer and Olla, 1998; Fréon et al., 1996; Wilson et al., 2003), time of day was used as a covariate in analyses of covariance tests to examine whether juveniles maintained consistent group structures. To test whether the environment differed among age categories, a single-factor ANOVA was conducted on each positional metric and environmental factor (Zar, 1996). Tukey's Honestly Significant Difference tests were then used to check for differences in each group metric and environmental factor based on juvenile pollock age class (Zar, 1996).

We used a path analysis (Kline, 1998) to develop interactions among aspects of juvenile pollock habitat (i.e., water temperature and depth), adult pollock densities, and euphausiid densities and to determine the influence these 
environmental factors had on group metrics within an age class. Path analysis is a structural equation model that tests relationships among measured variables and determines whether there are any meaningful patterns in the data by examining the overall impact of one variable on another by considering both the direct (e.g., impact of variable 1 on variable 3 ) and indirect (e.g., impact of variable 1 on variable 3 via variable 2) paths (Streiner, 2005). An extension of multiple regression, path analysis allows some variables (i.e., variables in the middle levels) to be both independent and dependent, and the strength of each of the indirect pathways is calculated as the product of the path-coefficients along that pathway (Streiner, 2005).

For this study, two a priori models were created to examine the influences of ecological and physical factors on both group position in the water column and group metrics. The first causal model addressed the influences of the 2 categories of environmental factors on group position in the water column and incorporated four levels of variables. The most basic level involved the depth of the eastern Bering Sea (EBS) shelf, the second level contained the water temperature, the third level contained the ecological factors (i.e., predator and prey), and the fourth level contained the vertical position of the group in the water column (i.e., group depth and distance above bottom; Fig. 4a). The second causal model addressed the influences of the 2 categories of environmental factors on group metrics and incorporated five levels of variables: those levels used in the first model plus a fifth level which contains group metrics (Fig. 4b). Because school depth and distance above bottom were collinear for our study area, only school depth was included in the fourth level of the second model. Both models assumed that influences move from bottom to top in the diagram and that each lower level variable had a path connecting it to each higher level variable; however, there was no connecting path between variables on the same level. The models assumed that temperature values were dependent on water column depth (e.g., Coachman and Charnell, 1979; Kinder and Schumacher, 1981; Schumacher and Stabeno, 1998) and in turn influenced the distribution of juvenile and adult fish as well as zooplankton (e.g., Swartzman et al., 1994; Bertrand et al., 2005; Ressler et al., 2014). Additionally, they assumed that the presence of predators (i.e., adult pollock) and prey (i.e., euphausiids) influenced the position of juvenile pollock in the water column (e.g., Olla and Davis, 1990; Sogard and Olla, 1993; Swartzman, 2001; Benoit-Bird, 2009). Within each age category, we performed a 4-level path analysis focused on group depth and distance above bottom for a total of 10 path analyses. Additionally, within each age category, we also performed a 5-level path analysis focused on each group metric, for a total of 35 path analyses.

Log transformations were performed on group metrics to stabilize the variance prior to all analyses. To avoid the assumption that significant associations equate to meaningful associations with such large sample sizes, effect sizes (i.e., total direct + indirect standardized regression coefficients) were used in lieu of t-values and p-values (Cohen, 1988; Rosnow and Rosenthanl, 1996) in the path analyses. Results from Tukey's Honestly Significant Difference tests were considered significant at alpha $\leq 0.05$.

\section{Results}

\subsection{Effects of age category on group position and structure}

Age-2 pollock formed the shallowest groups (Fig. 5a), farthest above the bottom (Fig. 5c). Age-1 pollock also formed shallow groups (Fig. 5a), but because they were found over relatively shallower areas of the shelf (Fig. 5b), they instead aggregated closer to the seafloor, at above-bottom distances similar to the other three age categories (i.e., similar to mix12, mix 23 , and age-3 fish; Fig. 5c).

Juvenile pollock maintained a relatively constant density and shape among age categories. Although volume-dependent group density $\left(\mathrm{fish} / \mathrm{m}^{3}\right.$ ) declined significantly as a function of fish age (Fig. 6e), there were no significant differences in average interfish distances relative to fish body size among all juvenile age categories (number of fish $/$ mean $\mathrm{BL}^{3}$; Fig. 6f). That is, smaller pollock formed denser groups because more fish could fit into a given volume, not because their interfish distances decreased. Roundness was constant across all age categories $(\bar{x}=1.7-1.8$; Fig. 6c), except mix $23(\bar{x}=1.9)$, and not correlated with other external group metrics $(r=0.35,-0.14$, and -0.11 , for length, height, and spread, respectively). This suggests a similar horizontal shape, irrespective of fish age and group size. By definition, when spread is inversely proportional to size, the shape is constant. Therefore, the inverse trends that existed between group height and group spread among age categories $(r=-0.97)$ also suggests a similar overall 3D shape (Fig. 6b, d).

Mixed age groups were no more variable internally than their older pure-aged cohorts. Mix 12 groups had the same internal heterogeneity as age-2 groups (Fig. 6g, h), even though mix 12 formed significantly longer groups (Fig. 6a). Likewise, mix 23 groups had the same internal heterogeneities as age-3 groups (Fig. 6g, h).

\subsection{Two scales of influence}

We used comparisons of means and path analyses to focus on different temporal and spatial scales of environmental influences as follows. The comparisons of means scrutinize all age categories simultaneously to measure the grouping and position behavior of juvenile pollock across age categories (i.e., regional responses). These results are indicative of longer-term responses of juvenile pollock to their environment across the study site and between years (e.g., "mix12 fish were found in the warmest waters compared to the other age classes of juvenile pollock"). In contrast, path analyses were indicative of how juvenile pollock groups responded to changes in their immediate environment (i.e., local responses). More precisely, path analysis scrutinizes one age category at a time. The results indicate the total effect environmental (i.e., physical and ecological) factors may have on both group structure and the position of the groups in the water within an age category (e.g., "mix12 groups were further off bottom when bottom waters at that location were colder").

For our study, comparison of means suggest juvenile pollock were grouping and positioning themselves by age class across the entire Bering Sea shelf based on the shelf's environment. However, path analyses suggest that at the specific location of each group, juvenile pollock were responding to immediate physical factors but not to immediate ecological factors. 


\section{A}
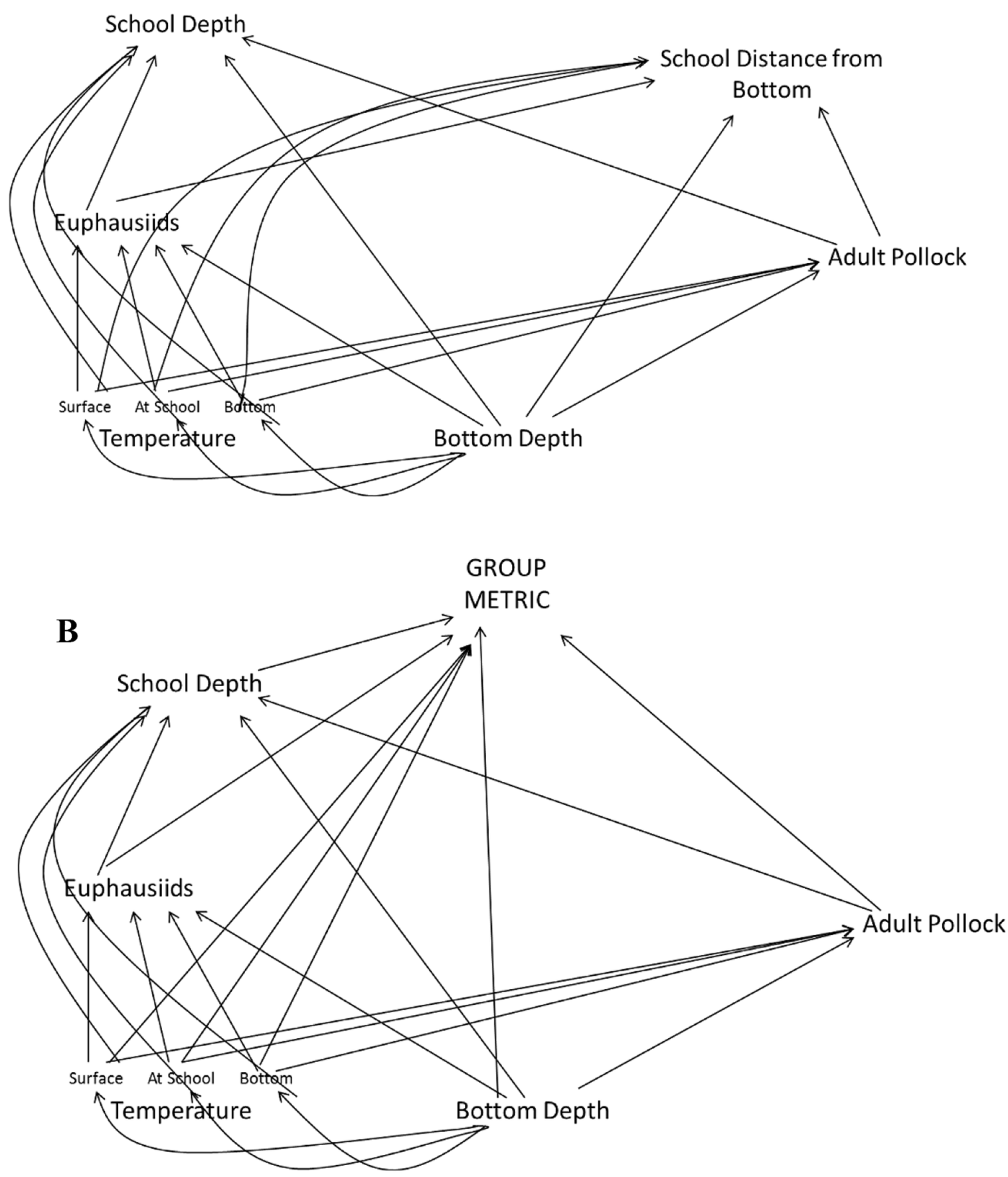

Fig. 4. (A) The 4-level causal model used to examine the influences of physical and ecological factors on group position in the water column within each age class and (B) the 5-level causal model used to examine the influences of physical and ecological factors on group metrics within each age class.

\subsection{Regional effects of the physical environment on juvenile pollock}

The physical environment may have influenced regional responses of juvenile pollock across age categories. Comparison of means show that within each year, groups of older juveniles were found in significantly cooler waters compared to the younger fish. Thus, mix 23 and age- 3 groups were in areas with cooler group and bottom temperatures than were age-1 groups in 2009 (Fig. 5g, h). Similarly, age-2 groups were in areas with cooler surface, group, and bottom temperatures than were mix12 groups in 2010 (Fig. 5f, g, h). 

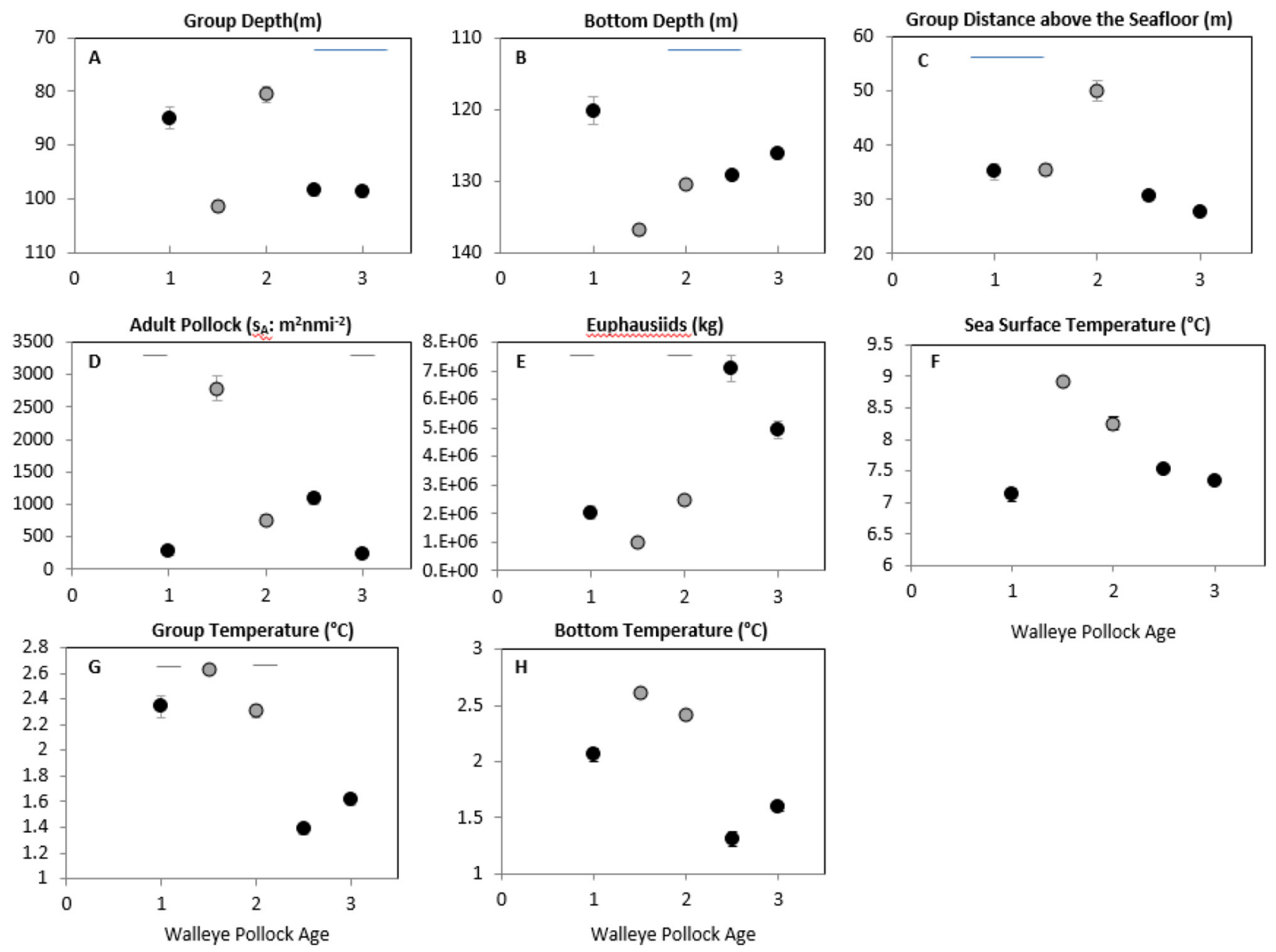

Fig. 5. Results of a single-factor ANOVA showing the local environment for each age class of juvenile walleye pollock (A, group depth; B, bottom depth ; C, group distance above the seafloor; D, adult pollock density; E, euphausiid density; F, sea surface temperature; G, group temperature; and $\mathrm{H}$, bottom temperature). The error bars represent $95 \%$ confidence intervals about the mean and are sometimes obscured by the symbol. Black circles represent means from 2009, and the gray circles represent means from 2010. Mix 12 results (e.g., groups with 1 and 2 year olds) are plotted between age 1 and age 2, and mix 23 results (e.g., groups with 2 and 3 year olds) are plotted between age 2 and age 3 . Lines above the symbols indicate no statistically significant differences were detected between those age groups based on Tukey's multiple comparison tests.

\subsection{Local effects of the physical environment on group position and structure}

The physical environment may have also influenced local responses of juvenile pollock. Path analyses show that within each age category, groups were found farther above bottom as the bottom got deeper (Tab. 2). Groups were also found further away from the seafloor (i.e., age $1, \operatorname{mix} 12, \operatorname{mix} 23$, and age 3 ) and the ocean surface (i.e., mix12 and mix23) when those waters, respectively, became cooler (Tab. 2).

The vertical position of juvenile walleye pollock groups in the water column was, in turn, associated with specific group structuring within an age category. As group depth increased (for age-1, mix 12, age-2, and age-3 fish) or bottom temperature decreased (for mix 23 fish), groups became vertically shorter, denser, and had more variation in horizontal internal density, although the degree of this response varied by age category (Fig. 7).

\subsection{Regional effects of the ecological environment on juvenile pollock}

The ecological environment may have also influenced regional responses of juvenile pollock across age categories. Comparison of means show that mix 12 groups were found in areas with considerably higher average adult pollock densities $\left(\bar{x}=2800 \mathrm{~s}_{\mathrm{A}}\right)$ compared to all other age categories $\left(\bar{x}=200-1200 \mathrm{~s}_{\mathrm{A}}\right.$; Fig. 5d) and they formed significantly longer groups (Fig. 6a). Additionally, older juveniles were detected in areas with significantly higher densities of euphausiids. That is, mix 23 and age- 3 groups were in areas of higher euphausiid densities than were age-1 groups in 2009; 
Table 2. Total effects (direct + indirect) of environmental factors on juvenile walleye pollock vertical position in the water column within each age class. No effects are in gray, small effects are in black, medium effects are bolded, and large effects are higlighted.

\begin{tabular}{l|l|cc|cc|cc|cc|cc|cc}
\hline \multicolumn{4}{c}{ Age 1 } & \multicolumn{4}{c}{ Mix 12 } & \multicolumn{2}{c}{ Age 2 } & \multicolumn{2}{c}{ Mix 23 } & \multicolumn{2}{c}{ Age 3 } \\
\hline \multirow{2}{*}{} & Biophysical & Group & Above & Group & Above & Group & Above & Group & Above & Group & Above \\
& Factor & Depth & Btm & Depth & Btm & Depth & Btm & Depth & Btm & Depth & Btm \\
\hline Physical & Bottom depth & 1.35 & 0.62 & 0.91 & 0.79 & -0.34 & 0.68 & -0.51 & 1.28 & $\mathbf{0 . 3 9}$ & 1.47 \\
& Surface temp & 0.11 & -0.15 & -0.31 & 0.33 & 0.04 & 0.03 & -0.59 & 0.60 & -0.10 & 0.15 \\
& Group temp & $\mathbf{- 0 . 3 7}$ & 0.50 & 0.07 & -0.07 & -0.04 & 0.03 & -0.32 & 0.33 & $\mathbf{- 0 . 3 6}$ & 0.52 \\
& Bottom temp & $\mathbf{0 . 4 8}$ & -0.65 & 0.31 & -0.34 & -0.29 & 0.24 & 0.23 & -0.23 & 0.58 & -0.85 \\
\hline Ecological & Adult pollock & -0.12 & 0.16 & 0.08 & -0.09 & 0.00 & 0.00 & -0.00 & 0.00 & -0.08 & 0.12 \\
& Euphausiids & -0.06 & 0.08 & 0.05 & -0.06 & 0.20 & -0.17 & -0.08 & 0.08 & -0.07 & 0.10 \\
\hline
\end{tabular}
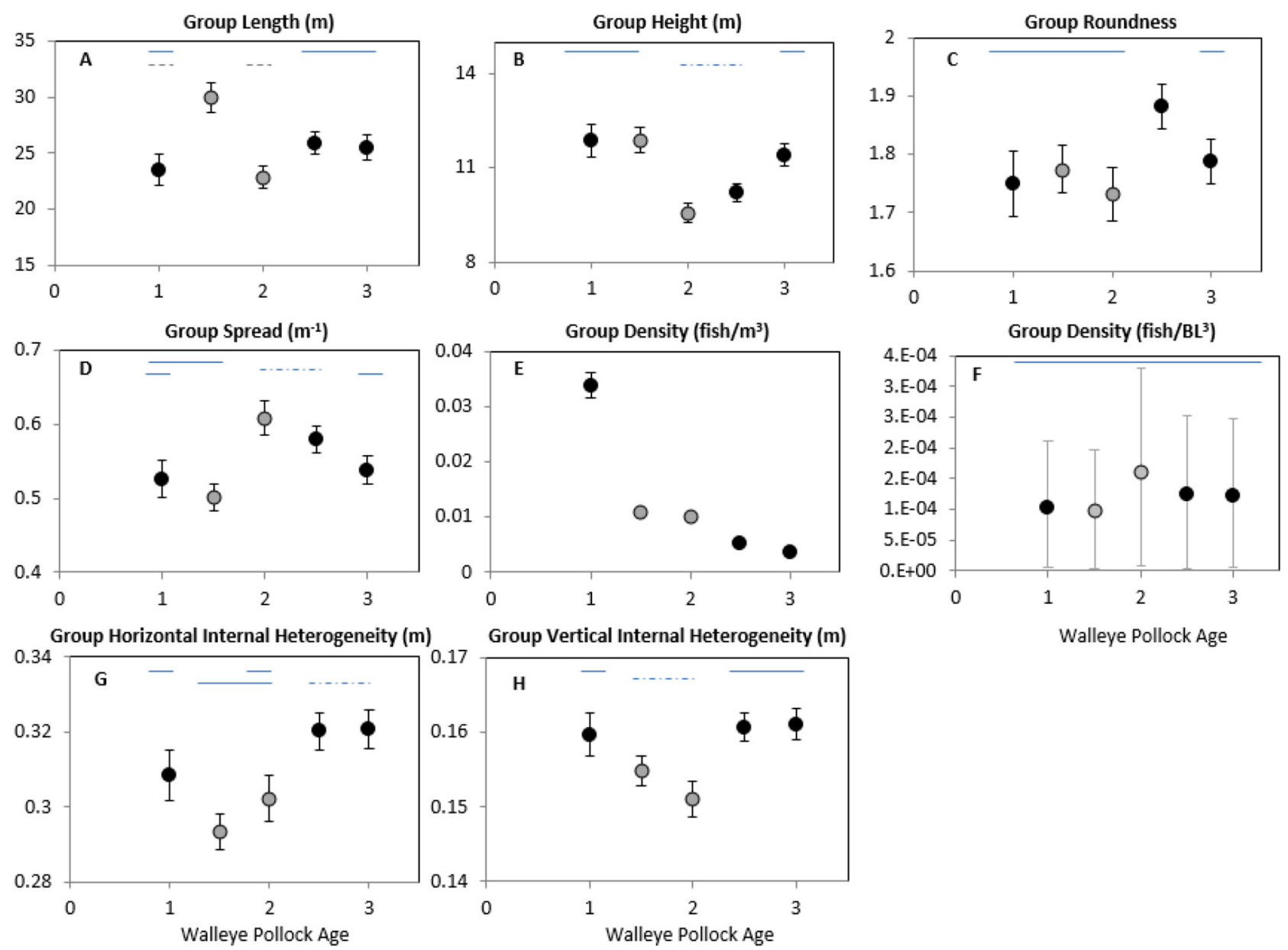

Fig. 6. Results of a single-factor ANOVA showing effects of juvenile pollock age on group metrics (A, length; B, height; C, roundness; D, roughness; E, volumetric density; F, density based on body length; G, horizontal internal heterogeneity; and H, vertical internal heterogeneity). The error bars represent $95 \%$ confidence intervals about the mean and are sometimes obscured by the symbol. Black circles represent means from 2009, and the gray circles represent means from 2010. Mix 12 results (e.g., groups with 1 and 2 year olds) are plotted between age 1 and age 2, and mix 23 results (e.g., groups with 2 and 3 year olds) are plotted between age 2 and age 3. Lines above the symbols indicate no statistically significant differences were detected between those age groups based on Tukey's multiple comparison tests. 
A

GROUP DENSITY
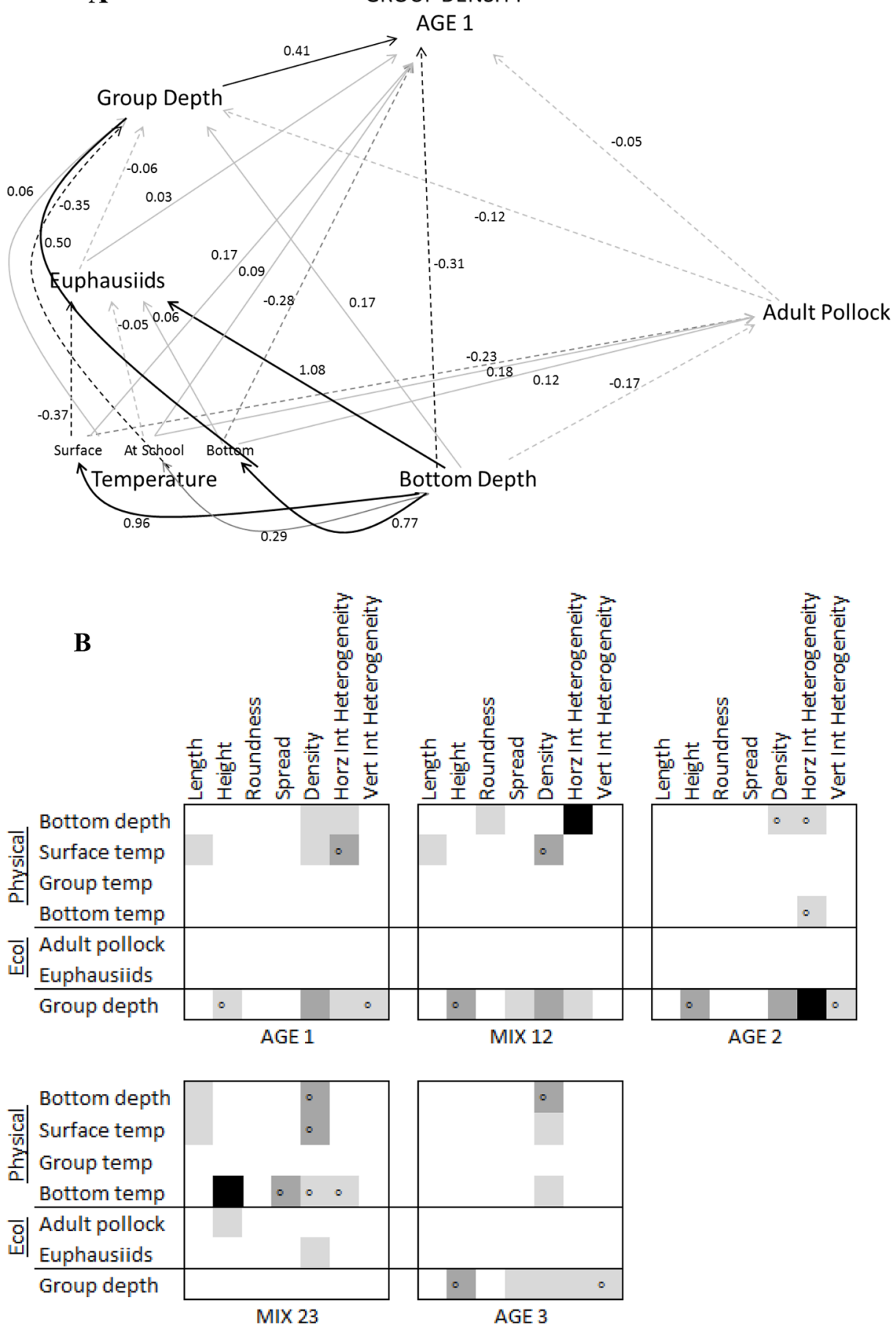

Fig. 7. (A) Direct effects of environmental factors on group density of age-1 pollock. This result is intended as an illustrative example of how direct effects culminate into total effects. Similar results for the other 34 path analyses are not shown. Larger effects are indicated by more bold arrows. Solid arrows represent positive effects and dashed arrows represent negative effects. (B) Total effects (direct + indirect) of environmental factors on size, shape, and internal structure of age-1, mix 12, age-2, mix 23 , and age-3 groups of juvenile walleye pollock. No effects $(0-0.20)$ are indicated by white fill, small effects $(0.20-0.35)$ are indicated by light gray fill, medium effects $(0.35-0.50)$ are indicated by dark gray fill, and large effects $(>0.50)$ are indicated by black fill. Positive effects are indicated by a solid fill, and negative effects are indicated by an open circle "o" within the fill. 
and age-2 groups were in areas with higher densities of euphausiids than were mix12 groups in 2010 (Fig. 6e).

\subsection{Local effects of the ecological environment on group position and structure}

Although the presence of adult pollock and euphausiids may have influenced regional responses of juvenile pollock, they did not seem to influence local responses of juvenile pollock. That is, for a given age category, there was little association between the ecological environment and both the vertical position of juvenile pollock groups in the water column and their group structure (Fig. 7b, Tab. 2). The path analysis results show that ecological factors only had an effect on a group vertical position in one instance (i.e., euphausiid density of age-2 group depth; Tab. 2), and only had an effect on a group metric in two instances (i.e., adult pollock density on mix 23 height and euphausiid density on mix 23 group density; Fig. 7b). In both cases the effect was small.

\section{Discussion}

The stability in a number of emergent patterns discernable at the scale of the group did not change across age categories or in the face of the measured ecological forcing. Juvenile pollock in the eastern Bering Sea maintained a relatively constant sizedependent density (number of fish/mean $\mathrm{BL}^{3}$ ), group $2 \mathrm{D}$ horizontal shape (i.e., roundness), and group 3D shape among age classes and between years. Additionally, mixed age groups were no more variable internally than their older pure-aged cohorts, even though mix 12 fish did form considerably longer groups. Stability in group architecture is not unique to juvenile pollock. Various fish species have been reported to maintain consistent interfish spacing based on body length (Pitcher and Partridge, 1979; Viscido et al., 2004; Newlands and Porcelli, 2008) and a consistent group shape regardless of fish age or size (Abrahams and Colgan, 1985; Coetzee, 2000; Muiño et al., 2003). Other studies have shown that the internal structure of fish groups can be highly consistent within a species (Paramo et al., 2007), regardless of the aggregation type (i.e., group or layer; Gerlotto et al., 2004).

Within an age category, there were no measured short-term juvenile pollock grouping structures associated with the general presence and proximity of potential predators (e.g., adult pollock) and prey (e.g., euphausiids). This suggests that if there were any effects of predator and prey on local juvenile pollock patterns, they were not discernable with the extent and temporal grain of our data. Behavioral reactions of fish to predators and prey depend on a variety of factors, including distance to the predator or prey, predator and prey behavior and group size, and physical features (e.g., turbidity and light levels: Cerri, 1983; Godin and Morgan, 1985; Lima and Dill, 1990; Godin, 1997; Utne, 1997; Gadomski and Parsley, 2005). For example, some species of fish do not react to a predator until the predator is within a given range (Näslund et al., 2016). Additionally, if fish do react to short-term environmental disturbances, the reactions can occur rapidly (i.e., within seconds) and the fish can recover relatively quickly (i.e., within several minutes; Gerlotto et al., 2006; De Robertis and Wilson, 2010; Bruintjes et al., 2016, Handegard et al., 2016,
Rieucau et al., 2016). At the average group depth of juvenile walleye pollock in this study - i.e., $100 \mathrm{~m}$ (depth mean $95 \mathrm{~m}$, median $98 \mathrm{~m}$, and mode $113 \mathrm{~m}$ ) - the along track resolution of the acoustic data is $7 \mathrm{~m}$ (constrained by ship speed and ping rate) and the athwart track resolution is approximately $5 \mathrm{~m}$ under the ship and $10 \mathrm{~m}$ for beams steered at $40^{\circ}$. At this depth, we cannot observe any behavioral-related changes in group metrics at scales smaller than this. Assuming groups of juvenile pollock were influenced by nearby predators or prey, these disturbances were too brief or occurred at finer scales than could be detected with our approach.

There were, however, short-term interactions between juvenile pollock and their physical environment that did persist for long enough periods of time or occurred at coarse enough scales to be detected with our approach. Juvenile pollock grouping structures were associated with the depth of the group, which in turn was associated with water temperature. Groups tended to move away from the seafloor (i.e., age 1, mix 12 , mix 23 , and age 3 ) or ocean surface (i.e., mix 12 and mix23) when the bottom or surface waters, respectively, became cooler. Groups became vertically shorter, denser, and had more variation in horizontal internal density as group depth increased (i.e., for age-1, mix 12, age-2, and age-3 fish), although the degree of this response varied by age category. Demersal predators of juvenile walleye pollock in the Bering Sea, such as adult pollock and arrowtooth flounder, increase in numbers with proximity to the seafloor (Bailey, 1989; Aydin and Mueter, 2007). Fish have been shown to increase antipredator responses in microhabitats with higher predation risk (Helfman and Winkelman, 1997; Brown et al., 2006). Group compaction, an antipredator tactic (Pitcher and Parrish, 1993; Sogard and Olla, 1997), might be favored by juvenile pollock when they are closer to the seafloor, in a habitat with greater numbers of demersal predators. Our study determined that densities of adult pollock had no local effect on juvenile pollock group structure, but we did not measure whether the vertical proximity of adult pollock had such an effect. An important facet for further investigation would be to determine if the vertical proximity of predators and prey, rather than absolute densities, influence the short-term response of juvenile pollock group structure.

Our results do suggest that juvenile pollock may be reacting to their ecological environment at larger (i.e., regional) temporal and spatial scales. First, group length was correlated with predator density. Relative to the other age classes, mix 12 groups were found in areas of the Bering Sea shelf that had the greatest densities of adult pollock, and they formed the largest (i.e., longest and tallest) groups. Increasing group size is a classic antipredator tactic (e.g., Hager and Helfman, 1991; Pitcher and Parrish, 1993; Krause and Ruxton, 2002; Couzin and Krause, 2003; Hoare et al., 2004; Wong and Rosenthal, 2005). Second, the age of the juvenile pollock was correlated with prey density. Specifically, older juveniles were found in areas of the Bering Sea shelf that had higher densities of euphausiids. This trend was especially notable within a season.

There were also regional patterns in the apparent association between, or at least tolerance of, water temperature on juvenile pollock distribution. Compared to the younger fish, older juveniles (mix23 and age-3 fish in 2009, age- 2 fish in 2010) were geographically distributed in areas of the Bering 
Sea shelf with relatively cooler water temperatures. Other studies suggest that younger juveniles may have actively avoided colder waters, while larger juveniles were more tolerant of it. During years when the eastern Bering Sea cold pool extended further southward, age-1 sized pollock shifted their distribution southward to avoid the cold pool, but there was no notable change in distribution of larger age-2 and age-3 sized juveniles (Barbeaux and Hollowed, 2018). Laboratory studies have demonstrated that older juveniles swam into cold water to feed and/or avoid predation, whereas younger fish did not (Olla and Davis, 1990; Sogard and Olla, 1993). Avoidance of colder water by age- 1 juveniles is likely related to their lower tolerance to thermal change as a function of body size (Olla et al., 1985; Olla and Davis, 1990; Sogard and Olla, 1993). Ressler et al. (2014) found that euphausiid density was higher in areas of the Bering Sea with cooler bottom temperatures, which were corroborated by our study results. In both years, the older juveniles were in areas with relatively cooler bottom temperatures and also higher densities of euphausiids. These older juveniles may have resided in areas of the Bering Sea shelf with cooler water, and vertically adjusted their position in the water column to help alleviate thermal disadvantage (e.g., moved further off bottom when bottom waters in that specific location became even cooler).

\section{Conclusion}

Our study was able to capture regional interactions between juvenile pollock and their ecological and physical environment more effectively than local interactions. This is likely due to the fact that most local interactions caused changes in fish behavior which were either too short-lived or occurred at finer scales that could be detected with the temporal grain or extent of our data (e.g., Levin, 1992; Schneider, 1994; Peterson and Parker, 1998). If so, to capture short-lived interactions, the ME70 would need to be on a stationary platform, allowing insonification of a given juvenile pollock group(s) over minutes to hours. This methodology has proven effective with other species of fish. For example, Gerlotto et al. (2006) used a multibeam echosounder on a stationary platform (i.e., a ship held on station for hours) to collect data describing short-term predation events (i.e., events less than half a minute) by sea lions, Arctocephalus australis and Otaria byronia, on anchovy, Engraulis ringens, schools. The third dimension from these types of data captured changes in group architecture - specifically changes in internal heterogeneity relative to ecological influences.

A few local interactions between walleye pollock and the physical environment caused changes in fish behavior that persisted long enough and at coarse enough scales to be detected with the power of our methodology. It was often metircs obtained with the third dimension (e.g., denser, more variation in horizontal internal density) that captured how the local environment (e.g., warmer bottom temperatures) caused changes in fish behavior (e.g., move toward the seafloor). This suggests that studies which focus on the physical environment may be useful in understanding fish grouping behavior, especially when the data will be collected by a calibrated multibeam echosounder (e.g., a ME70) positioned on a moving platform. Additionally, the third dimension from "snapshots" of fish groups obtained with the ME70 was used to describe juvenile pollock grouping patterns that were the most stable across age categories (i.e., average values for size-dependent density and roundness were the same across age categories), regardless of short-term ecological and physical forcing. Assuming the values are species-specific, this result may prove helpful to future efforts using acoustics to discriminate juvenile pollock from co-occurring aggregated species, such as capelin, Mallotus villosus, or rockfishes (Sebastes spp.; Jones et al., 2017).

Acknowledgments. We thank the scientists and crew of the NOAA ship Oscar Dyson for their hard work in helping with the data collection. We thank James Ha for his statistical input and Anne Hollowed for valuable comments and remarks on earlier drafts of this paper. Reference to trade names or commercial firms does not constitute U.S. government endorsement.

\section{References}

Abrahams MV, Colgan PW. 1985. Risk of predation, hydrodynamic efficiency and their influence on school structure. Environ Biol Fish 13: 195-202.

Aydin K, Mueter F. 2007. The Bering Sea-a dynamic food web perspective. Deep-sea Res Part II: Top Stud Oceanogr 54: 25012525.

Bailey KM. 1989. Interaction between the vertical distribution of juvenile walleye pollock Theragra chalcogramma in the eastern Bering Sea, and cannibalism. Mar Ecol Prog Ser 53: 205-213.

Baird TA, Ryer CH, Olla BL. 1991. Social enhancement of foraging on an ephemeral food source in juvenile walleye pollock, Theragra chalcogramma. Environ Biol Fish 31: 307-311.

Barange M. 1994. Acoustic identification, classification and structure of biological patchiness of the edge of the Aguhas Band and its relation to frontal features. S Afr J Mar Sci 14: 333-347.

Barbeaux SJ, Hollowed AB. 2018. Ontogeny matters: climate variability and effects on fish distribution in the eastern Bering Sea. Fish Oceanogr 27: 1-15.

Benoit-Bird KJ. 2009. Dynamic 3-dimensional structure of thing zooplankton layers is impacted by foraging fish. Mar Ecol Prog Ser 369: 61-76.

Berdahl A, Torney CJ, Ioannou CC, Aria JJ, Couzin ID. 2013. Emergent sensing of complex environments by mobile animal groups. Science 229: 574-576.

Bertrand A, Barbieri MA, Gerlotto F, Leiva F, Córdova J. 2006. Determinism and plasticity of fish schooling behavior as exemplified by the South Pacific jack mackerel Trachurus murphyi. Mar Ecol Prog Ser 311: 145-156.

Bertrand A, Guitérrez M, Bertrand S, Espinoza P, Gerlotto F, Ledesma J, Quesquén R, Alza L, Peraltilla S, Chipollini A, Chavez F. 2005. How fish habitat suitability does shape the 3D spatial organization of anchovy across scales? ICES Annual Conference, Aberdeen, UK, 20-24/09/2006, ICES CM/U:10.

Bodholt H, Solli H. 1992. Split beam techniques used in Simrad EK500 to measure target strength. In: World Fisheries Congress, May 1992, Athens, Greece, pp. 16-31.

Brown GE, Rive AC, Ferrari MCO, Chivers, DP. 2006. The dynamic nature of antipredator behavior: pretty fish integrate threatsensitive antipredator responses within background levels of predation risk. Behav Ecol Sociobiol 61: 9-16. 
Bruintjes R, Purser J, Everley KA, Mangan S, Simpson SD, Radford AN. 2016. Rapid recovery following short-term acoustic disturbance in two fish species. Roy Soc Open Sci 3: 150686.

Bumann, D, Krause J, Rubenstein D. 1997. Mortality risk of spatial positions in animal groups: the danger of being in the front. Behaviour 134: 1063-1076.

Cantor M, Farine DR. 2018. Simple foraging rules in competitive environments can generate socially structured populations. Ecol Evol 8: 4979-4991.

Cerri RD. 1983. The effect of light intensity on predator and prey behaviour in cyprinid fish: factors that influence prey risk. Anim Behav 31: 736-742.

Clark PJ, Irwig K, Wobke W. 1997. Emergent properties of teams of agents in the Tileworld. Lect Notes Comp Sci 1209: 164-176.

Coachman LK, Charnell RL. 1979. On laternal water mass interaction - a case study, Bristol Bay, Alaska. J Phys Oceanogr 9: 278-297.

Coetzee J. 2000. Use of a shoal analysis and patch estimations system (SHAPES) to characterize sardine schools. Aquat Living Resour 13: $1-10$.

Cohen J. 1988. Statistical power analysis for the behavioral sciences. 2nd edn., Hillsdale, New Jersey: Lawrence Erlbaum Associates.

Conradt L, Krause J, Couzin ID, Roper TJ. 2009. "Leading according to need" in self-organizing groups. Am Nat 173: 304-312.

Couzin ID, Krause J. 2003. Self-organization and collective behavior in vertebrates. Adv Stud Behav 32: 1-75.

Couzin ID, Krause J, Franks NR, Levin SA. 2005. Effective leadership and decision-making in animal groups on the move. Nature 433: 513-516.

Couzin ID, Krause J, James R, Ruxton GD, Franks NR. 2002. Collective memory and spatial sorting in animal groups. $J$ Theor Biol 218: 1-11.

Cutter GR, Demer, DA. 2007. Accounting for scattering directivity and fish behavior in multibeam-echosounder surveys. ICES J Mar Sci 64: 1664-1674.

DeBlois EM, Rose GA. 1995. Effect of foraging activity on the shoal structure of cod (Gadus morhus). Can J Fish Aquat Sci 52: 2377-2387.

De Robertis A, Handegard NO. 2012. Fish avoidance of research vessels and the efficacy of noise-reduced vessels: a review. ICES J Mar Sci 70: 34-45.

De Robertis A, McKelvey DR, Ressler PH. 2010. Development and application of an empirical multifrequency method for backscatter classification. Can J Fish Aquat Sci 67: 1459-1474.

De Robertis A, Wilson CD. 2010. Silent ships sometimes do encounter more fish. 2. Concurrent echosounder observations from a freedrifting buoy and vessels. ICES J Mar Sci 67: 996-1003.

Diner N. 2001. Correction on school geometry and density: approach based on acoustic image simulation. Aquat Living Resour 14: 211-222.

Dwyer DA, Bailey KM, Livingston PA. 1987. Feeding habits and daily ration of walleye pollock (Theragra chalcogramma) in the eastern Bering Sea, with special reference to cannibalism. Can J Fish Aquat Sci 44: 1972-1984.

Foote KG, Traynor JJ. 1988. Comparison of walleye pollock targetstrength estimates determined from in situ measurements and calculations based on swimbladder form. J Acoustic Soc Am 83: 9-17.

Fréon P, Gerlotto F, Soria M. 1996. Diel variability of school structure with special reference to transition periods. ICES J Mar Sci 53: 459-464.

Gadomski DM, Parsley MJ. 2005. Vulnerability of young white sturgeon, Acipenser transmontanus, to predation in the presence of alternative pretty. Environ Biol Fish 74: 389-396.
Gerlotto F, Bertrand S, Bez N, Gutiérrez M. 2006. Waves of agitation inside anchovy schools observed with multibeam sonar: a way to transmit information in response to predation. ICES J Mar Sci 63: 1405-1417.

Gerlotto F, Castillo J, Saavedra A, Barbieri MA, Espejo M, Cotel P. 2004. Three-dimensional structure and avoidance behavior of anchovy and common sardine schools in central southern Chile. ICES J Mar Sci 61: 1120-1126.

Gerlotto F, Paramo J. 2003. The three-dimensional morphology and internal structure of clupeid schools as observed using vertical scanning multibeam sonar. Aquat Living Resour 16: 113-122.

Godin J-GJ. 1997, Evading predators. In: Godin J-GJ (ed.). Behavioural ecology of teleost fishes. Oxford: Oxford Universit Press, pp. 191-236.

Godin, J-GJ, Morgan MJ. 1985. Predator avoidance and school size in a cyprinodontid fish, the banded killifish (Fundulus diaphanous Lesueur). Behav Ecol Sociobiol 16: 105-110.

Grünbaum D, Viscido SV, Parrish JK. 2005. Extracting interactive control algorithms from group dynamics of schooling fish. Lect Notes Control Inf 309: 103-117.

Guttal V, Couzin ID. 2010. Social interactions, information use, and the evolution of collective migration. Proc Natl Acad Sci 107: 16172-16177.

Hager MC, Helfman GS. 1991. Safety in numbers: shoal size choice by minnows under predatory threat. Behav Ecol Sociobiol 29: 271-276.

Hamilton WD. 1971. Geometry for the selfish herd. J Theor Biol 31: 295-311.

Handegard NO, Holmin AJ, Rieucau G. 2016. Method to observe large scale behavioural waves propagating through fish schools using 4D sonar. ICES J Mar Sci 74: 804-812.

Hein AM, Rosenthal SB, Hagstrom GI, Berdahl A, Torney CJ, Couzin ID. 2015. The evolution of distributed sensing and collective computation in animal populations. eLife: e10955.

Helfman GS, Winkelman DL. 1997. Threat sensitivity in bicolor damselfish: effects of sociality and body size. Ethology 103: 369-383.

Hemelrijk CK, Kunz H. 2005. Density distribution and size sorting in fish schools: an individual-based model. Behav Ecol 16: 178-187.

Hoare DJ, Couzin ID, Godin GJ, Krause J. 2004. Context-dependent group size choice in fish. Anim Behav 67: 155-164.

Holmin AJ, Handegard NO, Korneliussen RJ, Tjøstheim D. 2012. Simulations of multi-beam sonar echos from schooling individual fish in a quiet environment. $J$ Acoust Soc Am 132: 3720-3734.

Honkalehto T, McCarthy A, Ressler P, Williams K, Jones D. 2012. Results of the acoustic-trawl Survey of Walleye Pollock (Theragra chalcogramma) on the US and Russian Bering Sea Shelf in June August 2010 (DY1006). AFSC Processed Report 2012-01, Alaska Fish. Sci. Cent., NOAA, Natl. Mar. Fish. Serv., 7600 Sand Point Way NE, Seattle WA 98115.

Honkalehto T, Ressler PH, Towler RH, Wilson CD. 2011. Using acoustic data from fishing vessels to estimate walleye pollock (Theragra chalcogramma) abundance in the eastern Bering Sea. Can J Fish Aquat Sci 68: 1231-1242.

Honkalehto T, McCarthy A, Ressler P, Stienessen S, Jones, D. 2010. Results of the acoustic-trawl Survey of Walleye Pollock (Theragra chalcogramma) on the US and Russian Bering Sea Shelf in June August 2009 (DY0909). AFSC Processed Report 2010-03, Alaska Fish. Sci. Cent., NOAA, Natl. Mar. Fish. Serv., 7600 Sand Point Way NE, Seattle WA 98115.

Honkalehto T, Williamson N, Jones D, McCarthy A, McKelvey D. 2008. Results of the echo integration-trawl survey of walleye pollock (Theragra chalcogramma) on the US and Russian Bering 
Sea shelf in June and July 2007. US Department of Commerce, NOAA Technical Memo. NMFS-AFSC-190.

Jolles JW, Boogert NJ, Sridhar VH, Couzin ID, Manica A. 2017. Consistent individual differences drive collective behaviour and group functioning of schooling fish. Curr Biol 27: 2862-2868.

Jones DT, Stienessen S, Lauffenburger N. 2017. Results of the acoustic-trawl Survey of Walleye Pollock (Gadus chalcogammus) in the Gulf of Alaska, June - August 2015 (DY2015-06). AFSC Processed Report 2017-03, Alaska Fish. Sci. Cent., NOAA, Natl. Mar. Fish. Serv., 7600 Sand Point Way NE, Seattle WA 98115.

Katz Y, Tunstrøm K, Ioannou CC, Huepe C, Couzin ID. 2011. Inferring the structure and dynamics of interactions in schooling fish. Proc Natl Acad Sci USA 108: 18720-18725.

Kim S. 1990. Status of fishery and science of Bering Sea walleye pollock: 1. History and importance of fisheries. Ocean Res 12: 117-128.

Kinder TH, Schumacher JD. 1981. Hydrographic structure over the continental shelf of the Southeast Bering Sea. In: Hood DW, Calder JA. (Eds.), The Eastern Bering Sea Shelf: Oceanography and Resources, University of Washington Press, Seattle, WA, pp. 31-52.

Kline RB. 1998. Principles and Practice of Structural Equation Modeling. New York: The Guilford Press.

Krause J, Ruxton GD. 2002. Living in Groups. Oxford, England: Oxford University Press.

Levin SA. 1992. The problem of pattern and scale in ecology. Ecology 73: 1943-1967.

Lima SL, Dill LM. 1990. Behavioral decisions made under the risk of predation: a review and prospectus. Can J Zool 68: 619-640.

Mackinson S, Nøttestad L, Guénette S, Pitcher T, Misund OA, Fernö A. 1999. Cross-scale observations on distribution and behavioural dynamics of ocean feeding Norwegian spring-spawning herring (Clupea harengus L.). ICES JMar Sci 56: 613-626.

MacLennan, DN, Fernandes PG, Dalen J. 2002. A consistent approach to definitions and symbols in fisheries acoustics. ICES J Mar Sci 59: 365-369.

Maes, J Ollevier F. 2002. Size structure and feeding dynamics in estauarine clupeoid fish schools: field evidence for the school trap hypothesis. Aquat Living Resour 15: 211-216.

Muiño, R, Carrera P, Iglesias M. 2003. The characterization of sardine (Sardina pilchardus Walbaum) schools off the Spanish-Atlantic coast. ICES J Mar Sci 60: 1361-1372.

Näslund J, Pettersson L, Johnsson JI. 2016. Behavioural reactions of three-spined sticklebacks to simulated risk of predation-effects of predator distance and movement. FACETS 1: 55-66.

Nero RW Magnuson JJ. 1989. Characterization of patches along transects using high-resolution $70-\mathrm{khz}$ integrated acoustic data. Can J Fish Aquat Sci 46: 2056-2064.

Newlands NK, Porcelli TA. 2008. Measurement of the size, shape and structure of Atlantic Bluefin tuna schools in the open ocean. Fish Res 91: 42-55.

Nøttestad, L, Axelsen BE. 1999. Herring schooling manoeuvres in response to killer whale attack. Can J Zool 77: 1540-1546.

Olla BL Davis MW. 1990. Behavioral responses of juvenile walleye pollock Theragra chalcogramma Pallas to light, thermoclines and food: possible role in vertical distribution. J Exp Mar Biol Ecol 135: 59-68.

Olla BL, Studholme AL, Bejda AJ. 1985. Behavior of juvenile bluefish Pomatomus saltarix in vertical thermal gradients: influence of season, temperature acclimation and food. Mar Ecol Prog Ser 23: 165-175.
Page LM, Espinosa-Pérez H, Findley LT, Gilbert CR, et al. 2013. Common and scientific names of fishes from the United States, Canada, and Mexico. $7^{\text {th }}$ Edition, Bethesda, Maryland: Spec Publ Am Fish Soc No. 34.

Paramo, J, Bertrand S, Villalobos H, Gerlotto F. 2007. A threedimensional approach to school typology using vertical scanning multibeam sonar. Fish Res 84: 171-179.

Paramo J, Gerlotto F, Oyarzun C. 2010. Three dimensional structure and morphology of pelagic fish schools. J Appl Ichthyol 26: 853-860.

Parrish JK, Edelstein-Keshet L. 1999. Complexity, pattern, and evolutionary trade-offs in animal aggregations. Science 284: 99-101.

Parrish JK, Viscido SV, Grünbaum D. 2002. Self-organized fish schools: an examination of emergent properties. Biol Bull 202: 296-305.

Peterson DL, Parker VT. 1998, Ecological scale: theory and applications. New York: Columbia University Press.

Pitcher TJ, Parrish JK. 1993, Functions of shoaling behavior in teleosts. In: Pitcher JT (Ed.), Behavior of Teleost Fishes 2nd edn. London, England: Chapman and Hall, pp. 363-439.

Pitcher, TJ, Partridge BL. 1979. Fish school density and volume. Mar Biol 54: 383-394.

Reid D, Scalabring C, Petigas P, Massé J, Aukland R, Carrera P, Gerogakarakos S. 2000. Standard protocols for the analysis of school based data from echo sounder surveys. Fish Res 47: 125-136.

Ressler PH, De Robertis A, Kotwicki S. 2014. The spatial distribution of euphausiids and walleye pollock in the eastern Bering Sea does not imply top-down control by predation. Mar Ecol Prog Ser 50: 111-222.

Ressler PH, De Robertis A, Warren JD, Smith JN, Kotwicki S. 2012. Developing an acoustic survey of euphausiids to understand tropic interactions in the Bering Sea ecosystem. Deep-Sea Res Pt II 6570: 184-195.

Rieucau G, Fernö A, Ioannou CC, Handegard NO. 2015. Towards of a firmer explantion of large shoal formation, maintenance and collective reactions in marine fish. Rev Fish Biol Fish 25: 21-37.

Rieucau G, Holmin AJ, Castillo JC, Couzin ID, Handegard NO. 2016. School level structural and dnamic adjustments to risk promote information transfer and collective evasion in herring. Anim Behav 117: 69-78.

Rose GA. 1993. Cod spawning on a migration highway in the northwest Atlantic. Nature 366: 458-461.

Rosnow RL, Rosenthanl R. 1996. Meta-analytic procedures for combining studies with multiple effect sizes. Psychol Bull 99: 400-106.

Ryer CH, Olla BL. 1992. Social mechanisms facilitating exploitation of spatially variable ephemeral food patches in a pelagic marine fish. Anim Behav 59: 403-409.

Ryer CH, Olla BL. 1998. Effect of light on juvenile walleye pollock shoaling and their interaction with predators. Mar Eco Prog Ser 167: 215-226.

Seebacher F, Krause J. 2017. Physiological mechanisms underlying animal social behavior. Philos Trans R Soc Lond B Biol Sci 372: 20160231.

Schneider DC. 1994, Quantitative ecology: spatial and temporal scaling. San Diego: Academic Press.

Schumacher JD, Stabeno PJ. 1998, The continental shelf of the Bering Sea. In: Robinson AR, Brink KH. (Eds.), The Sea: The Global Coastal Ocean: Regional Studies and Synthesis, New York: John Wiley and Sons, pp. 789-822. 
Similä T, Ugarte F. 1993. Surface and underwater observations of cooperatively feeding killer whales in northern Norway. Can $J$ Zool 71: 1494-1499.

Simmonds J, MacLennan D. 2005, Underwater Sound. In: Fisheries Acoustics Theory and Practice, 2nd edn. Oxford, England, Blackwall Science.

Simrad 2004. Simrad ER60 scientific echo sounder operator manual. Horten, Norway: Simrad Subsea A/S.

Sogard SM, Olla BL. 1993. Effects of light, thermoclines and predator presence on vertical distribution and behavioral interaction of juvenile walleye pollock, Theragra chalcogramma Passas. J Exp Mar Biol Ecol 167: 179-195.

Sogard SM, Olla BL. 1997. The influence of hunger and predation risk on group cohesion in a pelagic fish, walleye pollock, Theragra chalcogramma. Environ Biol Fish 50: 405-413.

Soria M, Bahri T, Gerlotto F. 2003. Effect of external factors (environment and survey vessel) on fish school characteristics observed by echosounder and multibeam sonar in the Mediterranean Sea. Aquat Living Resour 16: 145-157.

Stabeno PJ, Kachel NB, Moore SE, Napp JM, Sigler M, Yamaguchi A, Zerbini AN. 2012. Comparison of warm and cold years on the southeastern Bering Sea shelf and some implications for the ecosystem. Deep-Sea Res Pt II 65-70: 31-45.

Stienessen SC, Parrish JK. 2013. The effect of disparate information on individual fish movement and emergent group behavior. Behav Ecol 24: 1150-160.

Stienessen SC, Wilson CD. 2008, Juvenile Walleye Pollock Aggregation Structure in the Gulf of Alaska. In: Kruse, GH, Drinkwater, K, Ianelli, JN, Link JS, Stram DL (Eds.), Resiliency of gadid stocks to fishing and climate change: 24th Lowell Wakefield Fisheries Symposium, University of Alaska Fairbanks, Fairbanks. Alaska Sea Grant College Program, pp. 271-287.

Stienessen SC. 2015. Information transfer, heterogeneity, and local environmental effects on emergent group patterns defining fish schools: perspectives from different scales of observation, School of Aquatic and Fishery Sciences, University of Washington, PhD dissertation.

Streiner DL. 2005. Finding Our Way: An Introduction to Path Analysis. Can J Psychiatry 50: 115-122.

Svensson PA, Barber I, Forsgren E. 2000. Shoaling behaviour of the two-spotted goby. J Fish Biol 56: 1477-1487.

Swain DT, Couzin ID, Ehrich Leonard N. 2015. Coordinated Speed Oscillations in Schooling Killifish Enrich Social Communication. J Nonlinear Sci 25: 1077-1109.

Swartzman G. 1997. Analysis of the summer distribution of fish schools in the Pacific Eastern Boundary Current. ICES J Mar Sci 54: $105-116$.

Swartzman G. 2001. Spatial patterns of Pacific hake (Merluccius productus) shoals and euphausiid patches in the California current ecosystem. In: Krause GH, Bez N, Booth Al, Dorn MW, Hills S, Lipcius RN, Pelletier D, Roy C, Smith SJ, Witherell D. (Eds.), Spatial Processes and Management of Marine Populations, University of Alaska Fairbanks, Fairbanks. Alaska Sea Grant College Program, pp. 495-512.

Swartzman G, Stuetzle W, Kulman K, Powojowski M. 1994. Relating the distribution of pollock schools in the Bering Sea to environmental factors. ICES J Mar Sci 51: 481-492.

Tien JH, Levin SA, Rubenstein DI. 2004. Dynamics of fish shoals: identifying key decision rules. Evol Ecol Res 6: 555-565.

Towler RH, Jech JM, Horne JK. 2003. Visualizing fish movement, behavior, and acoustic backscatter. Aquat Living Resour 16: 277-282.

Traynor JJ. 1986. Midwater abundance of walleye pollock in the eastern Bering Sea, 1979 and 1982. Int North Pac Fish Comm Bull 45: 121-135.

Trenkel VM, Mazauric V, Berger L. 2008. The new fisheries multibeam echosounder M E70: description and expected contribution to fisheries research. ICES J Ma. Sci 65: 645-655.

Utne ACW. 1997. The effect of turbidity and illumination on the reaction distance and search time of the marine planktivore Gobiusculus flavescens. J Fish Biol 50: 926-938.

Viscido SV, Parrish JK, Grünbaum G. 2004. Individual behavior and emergent properties of fish schools: a comparison of observation and theory. Mar Ecol Prog Ser 273: 239-249.

Viscido SV, Parrish JK, Grünbaum D. 2005. The effect of population size and number of influential neighbors on the emergent properties of fish schools. Ecol Model 183: 347-363.

Viscido SV, Parrish JK, Grünbaum D. 2007. Factors influencing the structure and maintenance of fish schools. Ecol Model 206: 153-165.

Walline PD. 2007. Geostatistical simulations of eastern Bering Sea walleye pollock spatial distributions, to estimate sampling precision. ICES J Mar Sci 64: 559-569.

Walline PD, Wilson CD, Hallowed AB, Stienessen SC. 2012. Shortterm effects of commercial fishing on the distribution and abundance of walleye pollock (Theragra chalcogramma). Can J Fish Aquat Sci 69: 354-368.

Williamson N, Traynor JJ. 1996. Application of a one-dimensional geostatistical procedure to fisheries acoustic surveys of Alaskan pollock. ICES J Mar Sci 53: 423-428.

Wilson CD, Hollowed AB, Shima M, Walline P, Stienessen S. 2003. Interactions between commercial fishing and walleye pollock. Alaska Fish Res Bull 10: 61-77.

Wong BBM, Roesethal GG. 2005. Shoal choice in swordtails when preferences conflict. Ethology 111: 179-186.

Zar JH. 1996, Biostatistical analysis, 3rd edn. Upper Saddle River, New Jersey: Prentice Hall.

Cite this article as: Stienessen SC, Wilson CD, Weber TC, Parrish JK. 2019. External and internal grouping characteristics of juvenile walleye pollock in the Eastern Bering Sea. Aquat. Living Resour. 32: 19 